\title{
Appraising the situation: a framework for understanding compassionate care
}

\author{
Stephanie Tierney ${ }^{1 *}$, Kate Seers ${ }^{1}$, Joanne Reeve ${ }^{2}$ and Liz Tutton ${ }^{1}$
}

\begin{abstract}
Background: Compassion in healthcare represents an ideal way of interacting with patients. It entails an active response to suffering, distress or discomfort that can be associated with people seeking health related support or treatment. However, reports from within healthcare highlight that compassionate care (CC) is not always achieved. It may be especially problematic when trying to work with a patient who seems unwilling or unable to engage with advice provided by a healthcare professional (HCP).

Methods: We conducted a grounded theory study to understand the meaning of CC for HCPs working with patients with type 2 diabetes. Data were collected between May-October 2015 using focus groups and individual interviews; 36 HCPs took part in total. For the current paper, we used constant comparison to analyse data from transcripts where participants talked about working with a 'non-adherent' patient.

Results: Analysis highlighted how appraisal of their encounter with a non-adherent patient could affect whether CC was seen as possible by participants. Therefore, we used a transactional model of emotions as a framework for understanding HCPs' narratives. This involved a consideration of their primary appraisal of such encounters, which participants said often resulted in a sense of threat, failure and rejection. Their secondary appraisals, which centred on coping resources, included problem-focused approaches (e.g. supporting the patient to plan how to move forwards in managing their health) and emotion-focused approaches (e.g. recognising change was hard, appreciating it may not be the right time for the patient to change). These appraisals could be modified by: a) gaining experience as a HCP; b) altering what was seen as professional success; c) their connection with the patient; d) how much autonomy they had in their job.
\end{abstract}

Conclusions: Our findings provide new insights and emphasise that CC in response to non-adherent patients is not determined solely by a HCP's innate nature, but can be affected by an individual's appraisal of this interaction and the resources he/she has available to cope. This has implications for the environment within which staff work.

Keywords: Grounded theory, Compassionate care, Non-adherence, Transactional model of emotions, Interviews, Focus groups

\section{Background}

At the start of the 21st Century, concern about a perceived decline in compassion within healthcare has been reflected in numerous articles in the media, academic publications and policy documents. Yet despite this plethora of recent writing, there has been "little curiosity about what compassion, especially in healthcare, actually entails. How does it work? How is it nourished? What does it involve for staff? Why is it hard to sustain?" [1].

\footnotetext{
*Correspondence: stephanie.tierney@warwick.ac.uk

${ }^{1}$ Royal College of Nursing Research Institute, University of Warwick, Coventry, England

Full list of author information is available at the end of the article
}

Compassionate care (CC) is often presented in an idealistic form - as something that simply and automatically takes place, but this superficial consideration of the concept means that $\mathrm{CC}$ risks being "little more than a rhetorical and political device" [2], rather than a concept that can change/improve how services are delivered and experienced. Therefore, we urgently need fresh insights and new thinking around this key aspect of healthcare.

Definitions of CC vary [e.g. 2-4], but most recognise a core role for the relief of suffering (distinguishing CC from related concepts such as empathy, sympathy and pity). Gilbert and Choden [5] describe two processes 
associated with compassion: a) an ability to be open, alert, sensitive to suffering, and b) taking action to do something to alleviate or prevent this state. Existing writing on $\mathrm{CC}$ often focuses on attitudes, beliefs and actions of individual healthcare professionals (HCPs). However, our research has highlighted the importance of recognising $\mathrm{CC}$ as a complex model of care - a system wide process that needs to acknowledge both the actions of HCPs alongside the relationships and environment in which these occur [6].

In this article, we seek to advance understanding of $\mathrm{CC}$ by considering a critical situation [7] that emerged within our recent research. Whilst analysis revealed the importance of organisational factors in enabling or disrupting CC, participants also mentioned a particular patient factor that made CC challenging; they spoke of the difficulty in maintaining $\mathrm{CC}$ for patients they perceived to be 'non-adherent' to medical recommendations (they used this term, rather than concordance, so we have also employed it within the paper). This critical situation offers potential for deeper exploration of staff understanding and motivation for delivering $\mathrm{CC}$ through an examination of the importance of attributions and coping responses when faced with such encounters.

\section{Methods}

\section{Design}

Findings in this paper are based on data generated from a grounded theory study exploring the meaning of $\mathrm{CC}$ for HCPs working with patients with type 2 diabetes. It focused on care for this condition because it calls for sustained patient interaction with health services, allowing for on-going opportunities for compassion to be offered or not. A presentation of a whole systems model we developed from this study, which recognises the complex dynamics enabling or inhibiting $\mathrm{CC}$, has been described elsewhere [6]. The current paper presents an in-depth reflection on a single topic from the primary analysis namely what participants said about $\mathrm{CC}$ and their interactions with non-adherent patients. This was prominent within the data we collected in terms of intensity of feelings raised and its regular depiction as a barrier to $\mathrm{CC}$.

\section{Sample}

We used a purposive sampling approach initially, seeking maximum variation in terms of HCPs' experience, role (professional and support workers) and location of work (primary and secondary care). As data collection progressed, theoretical sampling was employed to find professionals who were newly qualified because people suggested their understanding of $\mathrm{CC}$ evolved as they became more experienced in their career. Participants worked across the UK and were recruited from two NHS Trusts and from relevant networks (e.g. Diabetes UK).

\section{Data collection}

Participants opted to engage in an individual interview or a focus group. Data collection took place during May-October 2015. Everyone gave informed consent to their involvement and to use of their anonymised quotations as part of dissemination. A topic guide was employed during interviews and focus groups, which outlined key areas to cover. Participants were asked questions such as:

- What do practitioners do to show compassion towards patients?

- How do you feel when you have been able to show compassion?

Data were audio-recorded and transcribed verbatim. All data collection was conducted by the first author; she does not have a clinical background and did not know participants prior to the study.

\section{Analysis}

The primary analysis used principles from grounded theory [8], including initial and focused coding, writing memos and constant comparison, to develop the full model. A focused code emerging from this analysis was 'facing nonchanging patients'. All data extracts $(n=87)$ assigned this label by the research team within the computer programme NVIVO were downloaded and reviewed. We undertook a secondary analysis of this specific code, informed by consideration of a framework developed by Lazarus and Folkman [9], who suggested that to understand emotions it is important to look at the transaction between person and environment:

"Threat, for example, is not solely a property of the person or the environment; it requires the conjunction of an environment having certain attributes with a particular kind of person who will react with threat when exposed to those environmental attributes."

Their model centres on the idea that how someone responds to an encounter is mediated by their interpretation of it on two levels:

- Primary appraisal: What does the situation mean for me? Is it a potential harm, threat, benefit or challenge? This can be shaped by how much stake individuals feel they have in an encounter, their personal motivations (goals, values) and beliefs about self and the world [9], which in turn affects the quality and intensity of their emotional response.

- Secondary appraisal: Can I cope? What resources are at my disposal? What control do I have over outcomes from this interaction? Hence, emotional 
response to a situation can be shaped by whether someone regards it as an encounter that: "(1) could be changed; (2) had to be accepted; (3) required more information before acting; (4) required holding oneself back from doing what one wanted to do" [9]. Lazarus and Folkman [9] wrote about a range of coping responses, including: confrontive, distancing, self-control, seeking social support, accepting responsibility, escape-avoidance, planful problemsolving, positive reappraisal. These can be divided into two broad coping approaches - problemfocused (addressing a facet of the problematic person-environment relationship) and emotionfocused (attempting to regulate feelings).

In line with this model, our data extracts were labelled as either primary or secondary appraisal by the first author; we also had the label 'modifier', which is not part of Lazarus and Folkman's model [9], but as described below appeared to be present within our data. The first author discussed her ideas with the rest of the team (who have a mixture of clinical and academic experience) to arrive at the findings presented below.

\section{Rigour}

To address rigour within the overall study, more than one person, from a range of backgrounds, took part in the analysis. In addition, NVIVO was used to manage and record decisions made throughout the research, providing a clear audit trail. We continued recruiting until we had gathered data from HCPs reflecting a range of perspectives in terms of role, experience and work setting.

\section{Results}

Interviews were conducted with $13 \mathrm{HCPs}$; they lasted between 40 and $75 \mathrm{~min}$. In addition, 4 focus groups were held, involving 23 people in total, which lasted between 40 and $80 \mathrm{~min}$. Two focus groups were attended by a mixture of HCPs, another with nurses and the last one was with podiatrists. Overall, 13 nurses (including specialist nurses), seven doctors (including consultants and general practitioners), six podiatrists, five healthcare assistants/support workers, three dieticians and two administrative staff participated in the study. Half worked in a hospital and the remainder in primary care or the community.

Participants taking part in focus groups (FG) and interviews (Int) described how facing a patient not making changes to their lifestyle could affect negatively their delivery of $\mathrm{CC}$ :

FG4 P8: “...it's frustration that they don't help themselves and it's very difficult to be compassionate with somebody who won't do anything to help themself."
Int 6: "...it does wear you down... when you see the same patient and nothing's happening...I would say that compassion, I wouldn't say it disappears...but it does go down quite a bit."

They were also clear that what was perceived as CC was not consistent and could shift from person to person and situation to situation:

FG3 P1: “...my perception of compassion and a doctor's conception of compassion may be two completely different things and a patient sitting there might favour one or the other. So what I would construe as compassion actually may not always be right."

As noted above, these descriptions of the variable nature of $\mathrm{CC}$ and the difficulties encountered when working with non-adherent patients were re-analysed using Lazarus and Folkman's framework [9] to provide a fresh insight on this topic. A summary of how this model captured the essence of what participants said is illustrated in Fig. 1. This is elaborated upon below and is the first time, to our knowledge, that this model has been used for thinking about how HCPs approach the provision of CC. Within this paper, we add to the model by considering factors that may modify appraisals of non-adherent patients, thereby affecting whether or not CC is expressed.

\section{Applying the transactional model}

Primary appraisal: When working with individuals who seemed unwilling or struggled to manage their condition, participants' primary appraisals included seeing the situation as a threat or potential harm to their sense of self as caring, to the positive feedback they anticipated from trying to help others, and/or to their professional reputation. Hence, they talked about being treated unfairly or taken for granted, feeling stuck or not getting their message across, having their advice rejected or not meeting professional goals of healing or improving someone's situation. They often mentioned feeling like a failure in such cases, again reflecting a perceived threat to their professional and personal sense of competence. Quotations illustrating these observations are presented in Table 1.

Only one person talked about seeing these patients as a positive challenge, which she related to personal rather than professional goals:

Int 8: "I'm a pleaser. I like to please....I often keep patients I find a challenge cause I like to bring them, get them to change. That's part of my personality...I'm a completer/finisher and I am competitive as well..." 


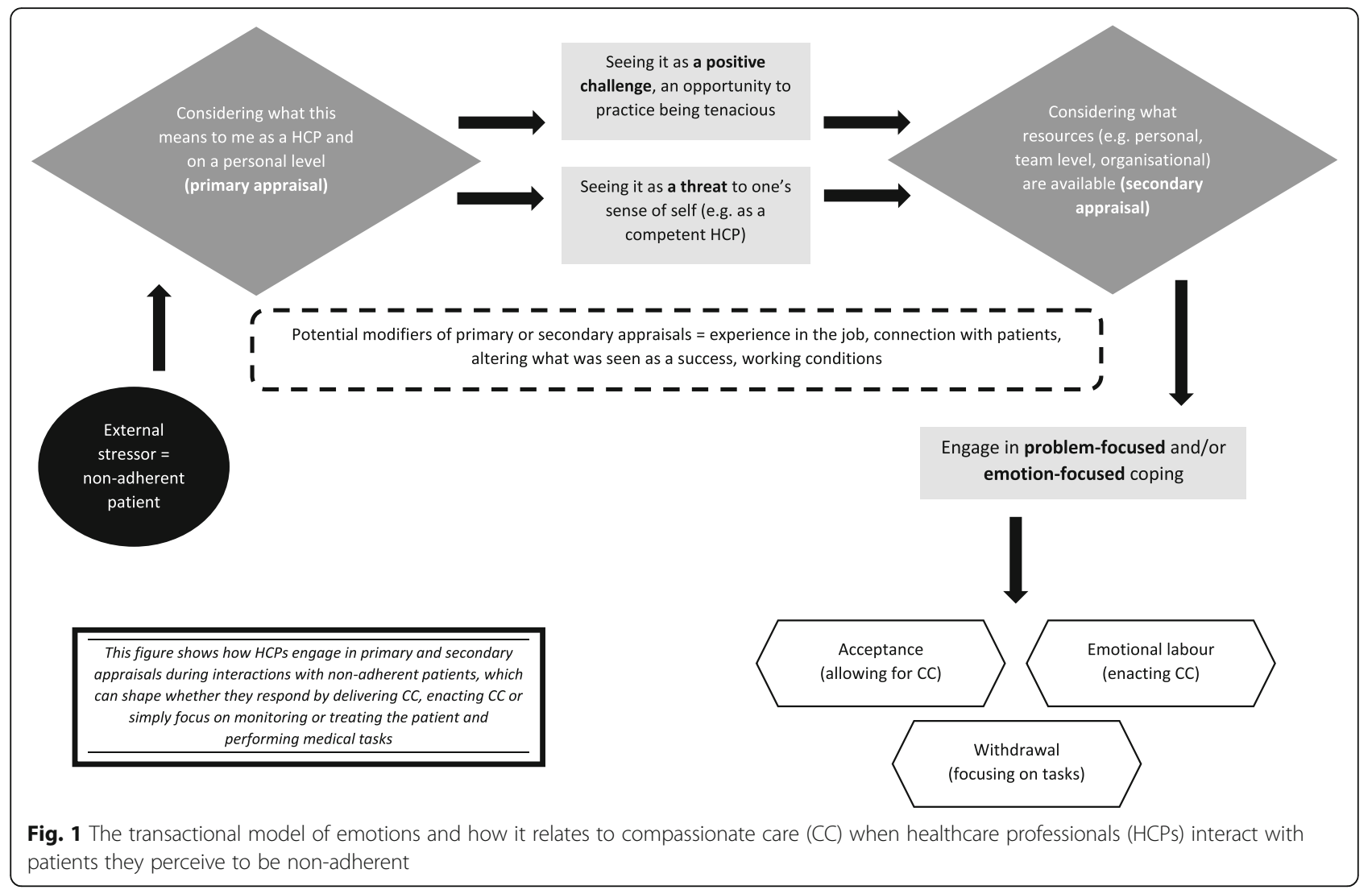

Secondary appraisal: In terms of secondary appraisals, problem- and emotion-focused coping processes were described. Problem-focused, as outlined in Table 2, included stressing the reality of what might happen if people did not control their blood sugars through education and information, and devising a plan about how to help by understanding someone's personal situation and goals.

Table 1 Data extracts highlighting primary appraisals of nonadherent patients

FG4 P8: "...you're not going to feel particularly compassionate towards people who are just not taking on board very simple advice, which will prevent them being the ones we see every week."

Int 4: "...you feel like then that you've failed if you've maybe not got that message across... it does make you feel like you've not done a very good job..."

Int 5: "... it's upsetting from a clinician's point of view because you always want to see people improving."

Int 6: "...we hate to see patients that are sort of not joining in with what we've said and we know the benefits from it so it does get very hard...I suppose it's just the fact that they haven't really took on board much that you've said."

Int 9: "...you've come to a brick wall... if they're not getting better or things are not improving, where do you actually go from there?"

Int 13: "That's frustrating... because medically speaking you want to do the best for the patient and the best means that their sugar levels need to be down..."
They also mentioned being thwarted in their endeavours to help, feeling powerless to change a situation and lacking time to understand a patient's decision-making. This could result in more emotion-focused coping, such as recognising how altering behaviour is hard, as is living with diabetes, appreciating it may not be the right time for someone to change, drawing on colleagues for support, celebrating small goals and believing they had done their best. Data reflecting these coping approaches are presented in Table 3.

Table 2 Data extracts highlighting problem-focused coping

FG2 P1: "I guess it's again communicating, going back to the start and working out why they haven't followed that method."

FG4 P3: "Sometimes you have to try scare tactics when you've had so many incidents and problems, you can say I know what this is gonna lead to if you carry on - amputation...I resort to that sometimes if I'm not getting through to them."

Int 3: "I think it's just trying to understand where that person is at the moment and what they are physically capable of and just saying... well I appreciate that and in the ideal world this, this and this should happen, but actually today we'll concentrate on this one element."

Int 9: "It's trying to tease out from them what changes they are willing to do, what's realistic for them and working with them... bring that motivation in... at the end of the day you can only do what you can do and being practical about things that you can change." 
Table 3 Data extracts highlighting emotion-focused coping

Int 2: "I've come to recognise we can make small strides and where we make them we should celebrate them... but there are some people you can't, sometimes the people you really can't motivate at all is because you cannot change their life situation."

Int 6: "...you have to realise that you're not gonna win everything and how far you can go with that patient, they have to make that change themselves."

Int 9: " ...kind of an open door policy with [colleagues] that you feel you can go and talk to them at any time if you've got a problem. I think that's been very important in my professional career that l've got somebody that I can approach and talk to and not feel that I'Il be judged in anyway."

Int 10: "...change is slow for some people and you just have to be prepared to go at their pace and some people will never change and I think it's their choice."

Int 11: "I do take into account the massive life changing things that we're asking patients to do and it is difficult and it's not something they can do for a couple of months and then go back to their previous lifestyle."

Int 13: "I would always look to get extra help from my team or maybe just discuss with a colleague as to what we can do for different patients."

Appraisal of the situation (personally and professionally) and whether one had the requisite skills to cope appeared to contribute to an acceptance of patients' unwillingness to change, with a compassionate response described as remaining available in such circumstances:

Int 2: “...you can't push against a closed door. I just say when you're ready, remember these things are here and that's what we're here for..."

Yet, in some cases, withdrawal could occur, to allow for emotional containment. One person said she sometimes retreated to her "professional shell" (Int 3) when faced with such cases. This was described as necessary so she could move on and attend to the needs of her wider caseload. CC was, therefore, replaced with a professional need to continue with tasks; consequently, a state of detachment might ensue:

FG4 P8: “...you do put your professional hat back on and say...well you know you shouldn't be doing $\mathrm{x}, \mathrm{y}$ and z... and that's when you do pull back...I do find it very hard to be compassionate with them when they're just, they just don't give a damn."

Alternatively, emotional labour [10] was performed in order to make patients feel at ease despite HCPs' frustration. Emotional labour entails altering or hiding how one really feels for the benefit of others and prioritising their need for safety and happiness [11]. The following quotations indicate this may happen when faced with a non-adherent patient, during which $\mathrm{CC}$ was enacted:
FG2 P3: “...patients are all different and some you will just bite your lips..."

Int 3: “...sometimes, the first thing is oh for God's sake, we told you. We discussed this...You can feel that but the patient shouldn't know that."

Int 4: "You are tantamount to being an actress sometimes as a nurse. You do kind of put on this face and this picture and you just get on with it."

Modifiers of appraisals: Narratives suggested that how HCPs appraised a situation and their ability to cope changed over time; as they gathered more experience in their work role, most participants appeared able to accept what was possible and were comfortable in drawing support from colleagues:

Int 9: "I think I'm more of a doer now. Before I would be worrying about things and not being practical about OK, what can I do about this? I've got more confidence now to go and speak to somebody about things or more experience because I've had other cases that I can compare it to... when I first started working 7 years ago, things I would have maybe got quite upset about or maybe taken home with me or worried about...7 years later I'm able to handle a bit better and maybe able to give a bit more advice and support because I've been through it maybe with other people."

One person talked about changing her view of what constituted success in her role as a nurse, which helped her to alter her primary appraisal of non-adherent patients as a threat:

Int 1: “...in my early days of nursing...people were coming back to see me and it was as if I hadn't helped them at all...I remember vividly wanting to walk away from diabetes nursing because I couldn't get it right. I really felt that I was failing people...I don't get cross now because I look at it through a different perspective...I've rephrased what success is for me. Success isn't the person in front of me does the right thing and gets the right target...the success for me is that they're happy with it...So success is about the view of the person around what they've achieved..."

The situation could also be appraised differently depending on how connected HCPs felt with a patient. 
Those participants (particularly specialist nurses and podiatrists) who saw patients on a regular basis felt that this prevented them from interpreting someone's behaviour as a threat because they knew the person well and felt they cared for her/him as an individual, not just a condition:

FG4 P8: “...the ones that we're really seeing regularly, we may feel differently towards the ones that come in for their annual review...you get into conversations, well what are you doing wrong and what are you getting right...So your levels of compassion alter in correspondence to the type of appointment..."

FG4 P1: “...those patients that become your favourites that you really care about, you do have unconditional [compassion] with them...some patients you really do care what happens to them so you will always keep going."

Nevertheless, these patients could come to be appraised as a threat if they were felt to be too dependent:

Int 4: "On a negative respect, people become quite clingy and oh well I only want to speak to so and so. So it's challenging to make sure that you've not made yourself indispensable because you have to have a day off, you have to go home."

Int 8: "But she's started to cling, you know, they what's the word when they start to cling to the professional, so she is standing out currently. I have had a few like that and to break that connection so it does remain professional..."

As well as length of time someone had to spend with patients, another potential modifier of HCPs' appraisals was the autonomy they had within their role and whether they felt able to change the structure of their working day:

Int 2: "I've had situations where the work pressures are, you know, really mounting up but I would like to think that I always make time [to talk to patients who are struggling]...I can set my own timetable a lot more and I can also quite often these scenarios would come up where the patient's not in a clinical, a clinic situation so we can expand what we're doing."

\section{Discussion}

Compassion is part of health terminology that people draw on to make sense of how to conduct themselves in a professional caring context. Data reported in this paper highlight that $\mathrm{CC}$ may be constructed in different environments in different ways, depending on individuals' appraisal of the situation before them. Hence, two people may vary in their response to the same encounter or the same person may reappraise what takes place in light of new information or resources. This dynamic is not necessarily reflected in policy documents that simply decree a need for CC [12]. In this sense, our research makes a novel contribution to debate on this topic by presenting $\mathrm{CC}$ through the lens of Lazarus and Folkman's transactional model [9]. Specifically, we drew on their notion of primary and secondary appraisals, and considered how, in relation to CC, these could be modified depending on interpersonal and contextual factors. Specific points highlighted by this work are outlined in Table 4.

Our research highlighted that a key factor affecting HCPs' appraisal of non-adherence is the environment in which they work. It has been noted that if a sense of peril or risk predominates, with a focus on outputs and targets, a "production-line mentality" may ensue, impeding people's psychological capacity for compassion [13]. Hence, although CC is said to call for an understanding of why someone may not follow medical advice and being able to imagine what a patient is going through [14], HCPs may lack the time to appreciate a person's unique situation and what diabetes means to him/her; consequently, they may appraise non-adherence as a significant threat to their professional proficiency and ability to help.

Perceiving non-adherence as a threat can prevent HCPs from 'being with' patients, whereby both parties co-operate and work together. This was emphasised during data collection by participants' actual use of the term 'non-adherent', which infers a privileging of HCPs over experiential knowledge. In contrast, concordance implies that an exchange about a condition's management has taken account of how to integrate self-care into a patient's unique life circumstances and activities [15]. In this sense, concordance is seen as patient-centred [16], whilst adherence may mean agreeing with a HCP's

Table 4 Key leaning points from our analysis (see also Fig. 1)

- For CC to be exhibited requires more than an inner drive within an individual HCP.

- Delivery of CC can be affected by appraisal of an immediate situation, what it means to self and professional identity, and what resources HCPs feel are available to them.

- Certain environmental or interpersonal factors can modify how HCPs appraise their interaction with a non-adherent patient; this has implications for CC delivery.

- Outcomes from HCPs' appraisal of a situation include acceptance, withdrawal or emotional labour. 
opinion and following their instructions, rather than eliciting genuine shared-decision making [17]. 'Being with' a patient may entail stepping away from health-related tasks for a moment and listening, being open to learning about a patient's situation in a non-judgmental, calm manner [18]. However, it may be hard to be present due to workload, tiredness and competing demands affecting concentration [19]. Likewise, taking a mechanistic approach to care, focusing on technology and technical skills, may put HCPs at risk of disengaging from the patient before them [20], resulting in staff doing for rather than being with patients [21].

It may be beneficial to assist HCPs to develop coping resources that allow for positive re-appraisal "I have done all I can but the patient is not ready to change yet") and to seek external support (expressing how they feel to colleagues) when faced with a patient who seems unwilling or unable to manage their condition. Takenfor-granted ways of acting may not hold for some patients depending on their circumstances and beliefs or values. Initiatives have been tried in practice (e.g. Balint groups and Schwartz rounds) to allow HCPs to reflect on interpersonal and emotional aspects of undertaking a caring role, but they are not available in every setting and do not deal with emotional distress in real-time, which may affect delivery of CC.

Study findings emphasised the emotional work undertaken by HCPs when faced with patients regarded as non-adherent. This links to previous writings on emotional labour, which defines strides individuals take in their work life to manage their emotions so they provide a publically-acceptable persona that meets with an organisation's expectations [10]. As part of this concept, emotional expression is seen as being governed by social rules, which may be specific to a setting. Employees come to learn the rules associated with their workplace by watching colleagues; in healthcare, this is reinforced by policy and institutional documents. It is argued that emotional work within healthcare is devalued because it is regarded as a natural activity [22], instinctive [23]. However, our research has highlighted that it involves a complex interplay between person-environment and cognitive-behavioural appraisals (see also [24]); this reiterates the point that $\mathrm{CC}$ is not necessarily a spontaneous or innate response but calls for reasoning and reflection. Hence, although actions associated with emotional work may be seen as minor and non-technical, they can require considerable personal investment and effort [25]. This was emphasised in the narratives from participants involved in our study, who often talked about the exhausting and testing nature of remaining compassionate when faced with patients who they appraised to be jeopardising their professional and personal goals and values by being, in the participants' words, 'non-adherent'.

\section{Conclusions}

In a study exploring the meaning of $\mathrm{CC}$ for HCPs caring for patients with type 2 diabetes, a key topic within participants' narratives was that of non-adherence among patients as a barrier to $\mathrm{CC}$. Our findings enable an appreciation of $\mathrm{CC}$ from a new angle; for the first time, we used a model of emotions and interpersonal relationships, outlined by Lazarus and Folkman [9], to consider the difficulties HCPs expressed about their interactions with such patients. Using this as a framework suggested that pre-requisites of CC include perceiving the situation as not too threatening to personal or professional status, or welcoming it as a challenge, and also feeling one has the resources available to cope. This may include valuing patients' right to choose for themselves how to behave, believing one is able to make a difference even if unable to influence someone's physical health, having colleagues who are supportive, and not feeling overwhelmed by external demands (e.g. targets, audits, being short staffed) so one has the headspace to form a plan of action. All participants talked about having the requisite health-related skills and knowledge, but $\mathrm{CC}$ was about how they evaluated and approached interactions, dealt with negative emotions and accepted blocks in improving a patient's condition. These are areas that could be addressed during training and post-qualification.

\section{Abbreviations \\ CC: Compassionate care; HCP: Healthcare professional}

\section{Acknowledgements}

We would like to thank all the HCPs who took part in an interview or focus group.

Funding

This study was funded by the Royal College of Nursing Research Institute.

\section{Availability of data and material}

The datasets generated and/or analysed during the current study are not publicly available because the ethics committee did not provide approval for the sharing of data in this way.

\section{Authors' contributions}

The first author was responsible for all data collection, led on data analysis and on writing this paper. The remaining authors played an equal role in interpretation of data and contributing to the final publication. All authors read and approved the final manuscript

\section{Competing interests}

The authors declare that they have no competing interests.

Consent for publication

Not applicable.

\section{Ethics approval and consent to participate}

Ethics approval was provided by the University of Warwick's Biomedical and Scientific Research Ethics Committee (Ref: REGO-2015-1424). All participants gave their consent to involvement and use of their anonymised quotations.

\section{Author details}

${ }^{1}$ Royal College of Nursing Research Institute, University of Warwick, Coventry, England. ${ }^{2}$ Social Science and Systems in Health, University of Warwick, Coventry, England. 
Received: 17 November 2016 Accepted: 22 December 2016

\section{Published online: 11 January 2017}

\section{References}

1. Ballatt J. Healthcare culture and intelligent kindness in practice. In: Hewison A, Sawbridge $Y$, editors. Compassion in nursing: theory, evidence and practice. London: Palgrave; 2016. p. 92-105.

2. Dewar B, Adamson E, Smith S, Surfleet J, King L. Clarifying misconceptions about compassionate care. J Adv Nurs. 2014;70:1738-47.

3. Schantz ML. Compassion: a concept analysis. Nurs Forum. 2007:42:48-55.

4. von Dietze E, Orbb A. Compassionate care: a moral dimension of nursing. Nurs Inq. 2000;7:166-74.

5. Gilbert P, Choden. Mindful compassion. London: Robinson; 2013.

6. Tierney S, Seers K, Tutton L, Reeve J. Delivering compassionate diabetic care: The feedback loop and its maintenance in an unaccommodating environment. Diabetic Med. 2016;33(Suppl 1):195.

7. Giddens A. Central problems in central theory. London: Hutchinson; 1979.

8. Charmaz K. Constructing grounded theory. 2nd ed. London: Sage; 2014.

9. Lazarus RS, Folkman S. Transactional theory and research on emotions and coping. Eur J Pers. 1987;1:141-69.

10. Hochschild AR. The managed heart: the commercialization of human feeling. Berkeley: University of California Press; 1983.

11. Yang FH, Chang CC. Emotional labour, job satisfaction and organizational commitment amongst clinical nurses: a questionnaire survey. Int J Nurs Stud. 2008:45:879-87.

12. Jones J, Pattison S. Compassion as a philosophical and theological concept. In: Hewison A, Sawbridge Y, editors. Compassion in nursing: theory, evidence and practice. London: Palgrave; 2016. p. 43-56.

13. Crawford P, Gilbert P, Gilbert J, Gale C, Harvey K. The language of compassion in acute mental health care. Qual Health Res. 2013;3:719-27.

14. Haslam D. More than kindness. J Compassionate Health Care. 2015;2:6.

15. Khair K. Compliance, concordance and adherence: what are we talking about? Haemophilia. 2014;20:601-3.

16. Moreau A, Aroles $V$, Souweine G, Flori M, Erpeldinger S, Figon S, Imbert $P$, Denis A, Iwaz J, Riou JP, Ploin D. Patient versus general practitioner perception of problems with treatment adherence in type 2 diabetes: from adherence to concordance. Eur J Gen Pract. 2009:15:147-53.

17. Snowden A, Martin C, Mathers B, Donnell A. Concordance: a concept analysis. J Adv Nurs. 2014;70:46-59.

18. Seno VL. Being-with dying: authenticity in end-of-life encounters. Am J Hosp Palliat Care. 2010;27:377-86.

19. Gabrielsson S, Savenstedt S, Olsson M. Taking personal responsibility: Nurses' and assistant nurses' experiences of good nursing practice in psychiatric inpatient care. Int J Ment Health Nurs. 2016;25:434-43.

20. Naef R. Bearing witness: a moral way of engaging in the nurse-person relationship. Nurs Philos. 2006; 7:146-56.

21. Whittemore R. Consequences of not 'knowing the patient'. Clin Nurse Spec. 2000;14:75-81

22. Gray B, Smith P. Emotional labour and the clinical setting of nursing care: the perspective of nurses in east London. Nurse Educ Pract. 2009;9:253-61.

23. Gray B. The emotional labour of nursing: defining and managing emotions in nursing work. Nurse Educ Today. 2009;29:168-75.

24. Folkman S, Lazarus RS. The relationship between coping and emotion: implications for theory and research. Soc Sci Med. 1988;26:309-17.

25. Staden $\mathrm{H}$. Alertness to the needs of others: a study of the emotional labour of caring. J Adv Nurs. 1998;27:147-56.

\section{Submit your next manuscript to BioMed Central and we will help you at every step:}

- We accept pre-submission inquiries

- Our selector tool helps you to find the most relevant journal

- We provide round the clock customer support

- Convenient online submission

- Thorough peer review

- Inclusion in PubMed and all major indexing services

- Maximum visibility for your research

Submit your manuscript at www.biomedcentral.com/submit
Biomed Central 